Monatsschrift f. Geburtshülfe u. Gynäkologie 1925;68:199-200

\title{
Ernst Bumm †
}

\section{VERLAG VON S. KARGER}

\section{BERLIN NW 6}

Ernst Bumm $\uparrow$.

Am 2. Januar 1925 ist dem Leben Ernst Bumms ein jähes Ende gesetzt worden. Bumm war am 20. Dezember nach ab-geschlossener Berufsarbeit zuversichtlichen Sinnes zur gewohnten Festfeier mit seiner Familie nach seiner Heimat aufgebrochen. Wohl hatten ihn in der letzten Zeit allerlei Beschwerden heim-gesucht; er wollte sich im Kreise der Seinen gründlich pflegen. Am Jahresende fühlte er sich plötzlich in München schwer er-krankt; er erlag den Folgen eines Gallenblasenempyem!

Bumms Ausscheiden bedeutet eine Katastrophe! Wohl stand er der Altersgrenze nicht mehr fern, aber seine kraftstrotzende Persönlichkeit schien die Gewähr zu geben, daß der 68jährige w.eit über die Zeit der Amtsführung hinaus unser Banner noch für lange Zeit hochtragen werde! Bumm bekannte sich freudig als Schüler Scansonis. Nach kurzer Dozentur, während welcher er mehrfach in den großen Kliniken, besonders von Wien und Berlin, Umschau gehalten, wurde er Nachf olger von Fehling in Basel, als dieser nach Halle übersiedelte. Fehling liefå ihn dann, als er selbst die Klinik W.A.Freunãs in Straßburg übernahm, nach Halle berufem 1904 erhielt Bumm die Gusseroivsche Professur in Berlin mit der gynäkologischen Charitéklinik. 1910 wurde er Nachf olger des überalteten Olshauscn. Die Universitäts - Frauenklinik ist durch Bumm vielseitig ausgestaltet worden. Der Marie-Simon-Pavilion wurde in Gebrauch genommen; es entwickelte sich hier ein Hochbetrieb, wie ihn nur ein Bumm mit übermenschlicher Ar-beitskraft zu meistern vermochte.

Bumm. führte sich mit dem Erfolg der Züchtung des Gono-kokkus Neisser in die Literatur ein. Mit vollster Energie trat er in den Kampf für die Aseptik ein und gegen die Wochenbettserkrankungen. Er schuf einen Grundriß zum Studium der Ge-burtshilfe, der durch die $\backslash$ ion ihm selbst meisterhaft gezeichneten Darstellungen zu einem Novum unserer Literatur wurde. Durch seine künstlerisch vollendete Bildsprache und die glänzende Diktion verdrängte dieser Grundriß überraschend schnell das damals noch den Markt beherrschende K. Schröäersche Lehr-buch, das Olshauscn trotz Beihilfe von J. Veil den entwickelten Ansprüchen des akademischen Leserkreises anzupassen nicht in der Lage war. Jahr auf Jahr folgten sich die neuen Auflagen! Bumms Forschertätigkeit machte sich auf alien Gebieten der Frauenheilkunde geltend. Er wurde der überragende Vor-kämpfer derselben. Durch eine vollendete Rednergabe, durch glänzende Operationen riß er seine Schüler und uns alle mit sich empor.

Monatssohrift f. Geburtshülfe u. Gynäkologie. Bel. LXVIII. Heft 4.

200

Ernst Bnmm †.

Bakteriologische Forschungen standen fortdauend im Vorder-grund seiner und seiner Mitarbeiter Bemühungen. Zuletzt be-kämpfte er das Kindbettfieber, einerseits durch die Sicherstellung der Diagnose, andererseits durch prophylaktische Impfungen. 
Mit Feuereifer beschäftigte sich Bumm mit der Strahlen-therapie, ohne sich je über die ihr gegenüberstehenden Be-denken und die so überraschenden Primärerfolge einer Illusion hinzugeben. Mit hochgemuter Wahrheitsliebe verschloß er sich nicht den ihr anhaftenden Gefahren und den so oft überraschend spat eintretenden Mißerfolgen. Freimütig bekannte er sich zu diesen und kehrte zur operativen Behandlung zurück, die in seiner Hand so hervorragende Erfolge gezeitigt hat.

Die Bevölkerungsprobleme und das Frauenstudium erörterte er von hohen Gesichtspunkten aus in richtunggebenden Dar-stellungen in seinen glänzenden Rectoratsreden.

Bumm war einer der glänzendsten Vertreter der deutschen Wissenschaft auf unseren nationalen und internationalen Kon-gressen. Die Berliner gynäkologische Gesellschaft verdankt Bumm die hohe Bedeutung ihrer Verhandlungen. Er wußte nicht nur eine Fülle von Anregungen beizubringen, in seiner vornehmen Art hielt er auch ihren bewährten gesellschaftlich hohen Ton fest. Seine Leitung des internationalen Gynäkologenkongresses 1912 führte zu dem großen Erfolge desselben, ebenso wie die des ersten Nachkriegskongresses der Deutschen gynäkologischen Gesellchaft (Berlin 1920).

Bumms vornehme Persönlichkeit fesselte weltweite Kreise der Hilfesuchenden.

Bei aller überreichen Arbeit blieb Bumm ein großzügiger,. vornehmender Lebensbejaher, - ein gottbegnadeter Künstler, dessen bildnerische Schöpfungen unsere Bewunderung erregen.

Unvergessen bleiben dem Ref. die gemeinsamen Streifzüge, in denen er in Rom mit ihm zu den Meisterwerken antiker Kunst herumziehen durfte.

Ernst Bumm wird in der Geschichte der Frauenheilkunde als die glänzendste Erscheinung an dem Beginn der Periode lebendig bleiben, in welcher die vorwiegend chirurgische Beeinflussung derselben durch die der biologischen Forschung abgelöst wurde. Bumms Persönlichkeit wird fur alle Mitlebenden und alle, die mit ihm in Berührung gekommen sind, als die eines hochvornehmen Mamies und treuen Freundes lebendig. bleiben! A. Martin. 


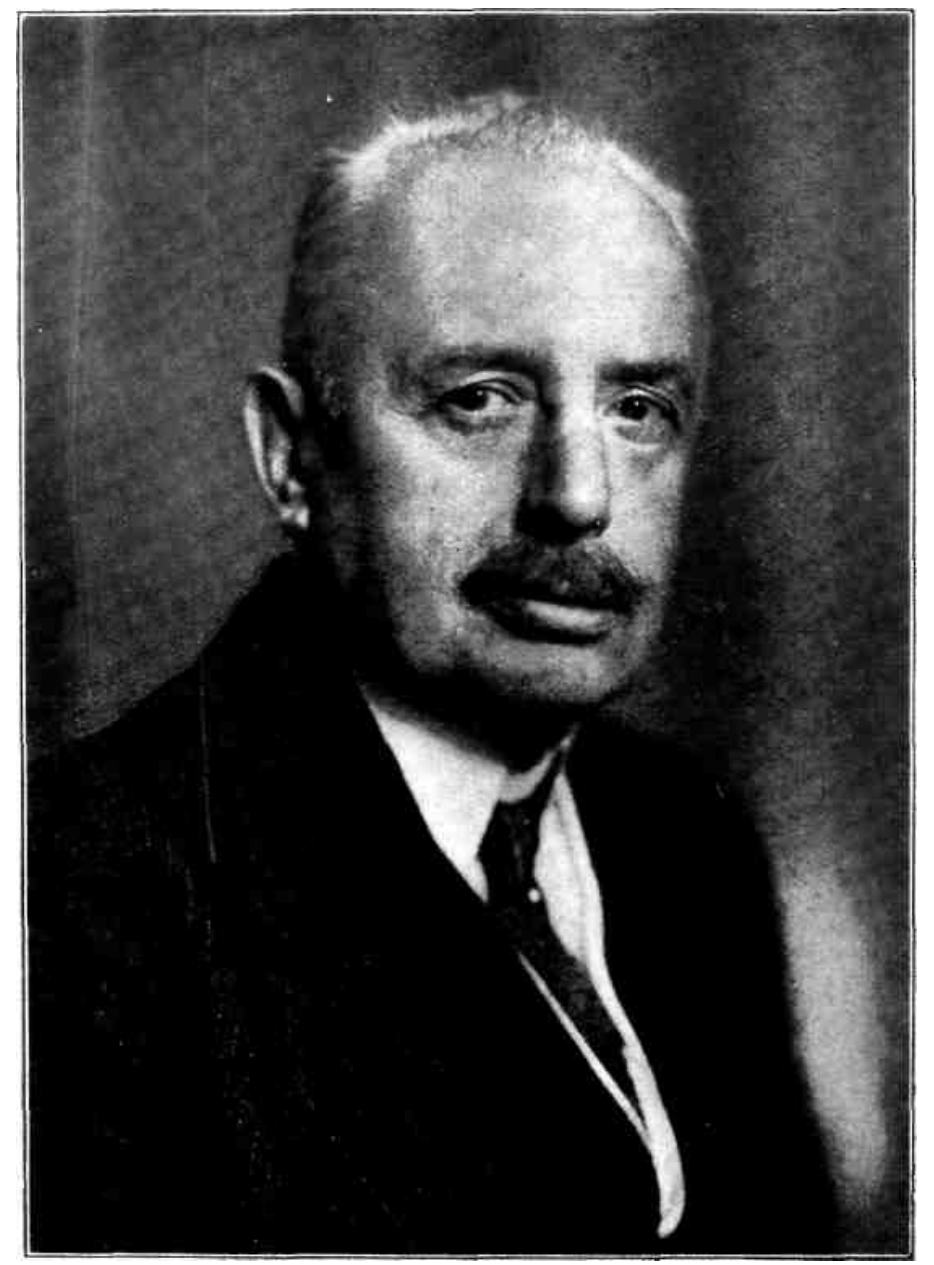

